\title{
OD VPRAŠANJ VOJAŠKE KULTURE DO ANALIZE VLOGE ANTROPOLOGOV V VOJSKI - DELO DONNE WINSLOW
}

\section{FROM THE QUESTIONS OF MILITARY CULTURE TO THE ANALYSIS OF ANTHROPOLOGISTS' ROLE IN THE ARMED FORCES - THE WORK OF DONNA WINSLOW}

Povzetek Donna Winslow je bila kanadska antropologinja, ki se je veliko ukvarjala s proučevanjem strukture in odnosov v sodobnih vojaških silah ter sodobne varnosti. Prispevek predstavlja pregled njenega raziskovanja, ki obsega tudi vrsto znanih in zanimivih del. Tako Donna Winslow razpravlja o posebnosti in sorodnosti vojske preostali družbi, razvoju kanadske vojske ter vplivu globalizacije na konflikte in koncepte varnosti. Posebej zanimiva so njena dela o obredih in kohezivnosti, ki izhajajo iz spremljanja kanadskega padalskega regimenta v Somaliji. Analizirala je tudi projekt Human Terrain in vprašanje uporabe znanosti v vojaške namene. Njena dela kažejo na družbeno angažirano znanstveno delo.

Ključne Donna Winslow, vojaška kultura, civilno-vojaško sodelovanje, afera v Somaliji, besede človekova varnost, vojna v Čečeniji, "sistem človekovega terena».

Abstract Donna Winslow was a Canadian anthropologist who, among other, focused her research interest on the structures and relations in contemporary military forces and contemporary security. In the article, a revision of her most known and interesting works is presented. Discussions are included about specialties of the military and similarities between the military and the rest of the society, about the development of Canadian military and about the impact of globalization on conflicts and security concepts. Among the most interesting things are the works on rituals and cohesion that arise from the inquiring of Canadian Airborne Regiment in Somalia. She also analysed the project Human Terrain and the issue of science in the military use. According to her works, it can be concluded that Donna Winslow was a socially active scientists.

Key words Donna Winslow, military culture, civil-military cooperation, Somalia Affair, human security, war in Chechnya, Human Terrain System 
Uvod V družboslovju se včasih zdi, da smo evropski raziskovalci kar precej okuženi z usmerjenostjo v proučevanje virov iz ZDA, čeprav seveda obstaja vrsta znanstvenikov iz drugih držav, ki prav tako objavljajo pomembne znanstvene ugotovitve. Ko je novembra 2010 umrla Donna Winslow, kanadska antropologinja, smo se avtorji prispevka zavedli, da njeno delo le površno poznamo, čeprav je ob srečanjih na nas naredila vtis s svojo strokovnostjo in zavzetostjo.

Profesorica Donna Winslow je bila kanadska antropologinja. Doktorirala je leta 1988 na Univerzi v Montrealu, službovala je na Univerzi v Ottawi in na Vriije Universiteit v Amsterdamu na Nizozemskem, učila pa še na nekaterih drugih kanadskih univerzah. Na koncu je delovala tudi na ameriški univerzi za vojaško logistiko. Vojsko je začela proučevati v sredini devetdesetih let prejšnjega stoletja, ko jo je kanadska vlada imenovala za tehnično svetovalko v komisiji za preiskavo pripadnikov kanadskih sil v Somaliji. Pozneje je opravljala še raziskave za Komisijo o vojaški kulturi, pri temah vojaške kulture in vojaške discipline je sodelovala tudi z Vojaškim raziskovalnim inštitutom ZDA in s kanadskim Oddelkom za nacionalno obrambo. Nazadnje je sodelovala pri projektu polkovnega sistema kanadske vojske. Kot antropologinja je terensko raziskovala v Kanadi, Jugovzhodni Aziji, na južnem Tihem oceanu in v Srednji Ameriki, s kanadsko vojsko pa je bila v operacijah na območju nekdanje Jugoslavije, Golanskem višavju in v Afganistanu. Objavila naj bi skoraj sto del - knjig, poglavij v knjigah, člankov v revijah, od katerih več kot polovica obravnava katerega od vidikov vojaške organizacije ali nacionalne in mednarodne varnosti. Še posebno velik odmev, ne le $\mathrm{v}$ akademski, temveč tudi v vojaški skupnosti, je imelo njeno proučevanje ravnanja kanadskih vojakov v Somaliji. Bila je cenjena članica mednarodnih strokovnih združenj in dobitnica pomembnih nagrad (Donna Winslow.com; Pinch 2010; Journal of Military and Strategic Studies).

Želja po pregledu in predstavitvi dela ter ugotovitev Donne Winslow nas tako poleg splošnega vpogleda v kulturo vojaških organizacij pripelje tudi do kanadske vojske. Kanadska zgodba na področju varnosti in obrambe je namreč nekoliko drugačna od ameriške, ki jo precej dobro poznamo. Tudi Kanada je velika država, ki pa ima dokaj majhno vojsko. Drži se je sloves »starih peacekeeperjev«, saj je bila kanadska obrambno-varnostna politika vedno privržena tradicionalnim mirovnim operacijam v slogu Lesterja B. Pearsona, nekdanjega kanadskega premierja in dobitnika Nobelove nagrade za mir leta 1957. Donna Winslow v svojih delih analizira in predstavlja kanadsko vojsko, kar pa je seveda ne omejuje, da ne bi proučevala širših varnostnih vprašanj. Vodilo tega prispevka je preprosto: proučiti in predstaviti delo Donne Winslow. Pri tej nalogi nam je zelo pomagala njena sistematičnost, saj je predstavljala svoja najboljša besedila na lastni spletni strani, za pomembne napotke pa smo hvaležni tudi Reneju Moelkerju.

\section{VOJAŠKA KULTURA}

Proučevanje vojaške kulture kot svojevrstne kulture, ki se razvije v okoliščinah, kakršne obstajajo znotraj oboroženih sil, je bilo pomemben sestavni del raziskovalnega opusa Donne Winslow. Donna Winslow je bila skupaj z Josephom L. Soetersom 
in Alise Weibull soavtorica poglavja o vojaški kulturi v Handbook of the Sociology of the Military (2003). Vojaško kulturo v kanadskih oboroženih silah je začela proučevati leta 1995, ko je opravila preiskavo za komisijo, ki je preiskovala delovanje kanadskih oboroženih sil v Somaliji.

Skupaj s priznanim britanskim vojaškim sociologom Christopherjem Dandekerjem z londonskega Kraljevega kolidža (King's College) je napisala članek o usmeritvah v vojaški kulturi. Prispevek je bil predstavljen na več konferencah, objavljen pa je bil leta 2000 v knjigi o podčastniškem zboru kanadskih oboroženih sil (glej Winslow in Dandeker, 2000, 1). Avtorja ugotavljata, da je ena od posledic sprememb v nacionalnem in mednarodnem varnostnem okolju po koncu hladne vojne ta, da je »človeška dimenzija « postala središčna tako v britanskih kot v kanadskih oboroženih silah. In ključno vprašanje, povezano s človeško dimenzijo oboroženih sil, je vprašanje, koliko je potrebno, da se vojaški način življenja razlikuje od načina življenja v civilni sferi družbe. Po eni strani imamo oborožene sile, ki morajo s svojim obstojem in organiziranostjo odgovoriti na zahteve strateškega okolja, po drugi pa morajo te iste oborožene sile poskrbeti za odzivnost na zahteve spreminjajoče se družbe, ki jo branijo, ki jih plačuje in brez podpore katere oborožene sile ne morejo preživeti. Identificirati je mogoče dve nasprotujoči si stališči, glede na prevladujoči politični nazor: konservativci dvomijo o spreminjanju vojaške kulture, da se ta čim bolj približa širši družbi, ker naj bi, po njihovem mnenju, to ogrozilo temeljno poslanstvo oboroženih sil, kar pa je vodenje vojn oziroma bojevanje. V nasprotju z njimi pa liberalci pričakujejo, da se oborožene sile podredijo vrednotam in sodobnim usmeritvam civilne družbe (glej Winslow in Dandeker, 2000, 2). Avtorja ugotavljata, da je najprimernejše pragmatično načelo, ki ga je mogoče uvrstiti med konservativnimi in liberalnimi stališči, ter da je zavajajoče trditi, da prilagoditev oboroženih sil civilnim družbenim vrednotam spodkopava vojaško učinkovitost.

V razpravi o vojaški kulturi se nedvomno postavlja vprašanje, kaj je tisto, kar naredi oborožene sile tako drugačne od civilne družbe. To so funkcionalni imperativi vojne in vojaških operacij. Po Sniderju (v Winslow in Dandeker, 2000, 3) je »vojskovanje (bojevanje) tisto, ki določa središčna prepričanja, vrednote in kompleksne simbolne formacije, ki opredeljujejo vojaško kulturo«. Po drugi strani pa obstajajo med civilnimi institucijami in oboroženimi silami tudi številne podobnosti, na primer pomembnost skupinskega dela, vodenje, zvestoba organizaciji, potreba po uporabi naprednih tehnologij. Avtorja to poimenujeta »institucionalna kakovost«. V institucionalnih organizacijah so glavno vodilo vrednote in ne trg. V oboroženih silah pripadniki opravljajo svoje naloge ne zato, da bi zaslužili, temveč da bi uresničili vrednote, ki zagotavljajo skupen namen celotne organizacije. Kot institucionalne organizacije imajo oborožene sile sebi lastno kulturo in poseben odnos s pripadniki. Avtorja (Winslow in Dandeker, 2000, 4) identificirata dve ključni vrednoti vojaške kulture. Prva temeljna vrednota vojaške kulture je subordinacija posameznika skupini. Druga pa je pripravljenost posameznika, da žrtvuje lastno življenje. V idealnih razmerah pripadniki vojske ti vrednoti prostovoljno sprejemajo skozi procese usposabljanja. Če je treba, pa se uporabi tudi prisila. »Vojska je specifična glede narave in razpona zahtev, ki jih postavlja do svojih pripadnikov« (ib.). 
Avtorja se v članku osredotočita na vpliv strateškega konteksta na civilno-vojaške odnose ter poskušata najti odgovor na vprašanje o smiselnosti nadaljnjega obstoja kanadskih in britanskih oboroženih sil skozi percepcijo domače (torej kanadske in britanske) javnosti. Ugotavljata, da britanska javnost ne zaznava neposredne vojaške grožnje, prednost pa pripisuje nevojnim bojnim nalogam oboroženih sil, npr. mirovne operacije ali vojaška pomoč ob humanitarnih operacijah. Kanada pa bo še naprej ZDA prepuščala glavno skrb za ozemeljske obrambne sisteme, kar ji bo omogočilo, da večino vojaških virov prej nameni za ohranjanje mednarodne varnosti kot nacionalne. Glavne grožnje nacionalni varnosti bodo ekonomske, informacijske, kriminalne, okoljske in teroristične in ne tradicionalne vojaške. In avtorja se pri tem sprašujeta, kakšno vlogo, če sploh, lahko oborožene sile igrajo v obrambi nacije pred temi grožnjami. Medtem ko ZDA, po mnenju avtorjev, natančno opredeljujejo, kdaj in za kakšne namene bodo uporabile lastne oborožene sile, pa je slika nekoliko drugačna v Kanadi, ki po njunem mnenju nima jasno opredeljenih nacionalnih interesov. »Brez specifičnih vitalnih interesov bodo kanadske oborožene sile še naprej delovale skladno s širokimi, nedoločljivimi cilji, ki bodo utemeljeni na kanadskih vrednotah.« (Winslow in Dandeker, $2000,6)$. Očitna je odsotnost povezanosti med obrambno in zunanjo politiko, kar močno otežuje nadaljnje obrambno načrtovanje. Po mnenju avtorjev kanadska zunanja politika postavlja več vprašanj glede vloge kanadskih oboroženih sil pri zagotavljanju mednarodne varnosti in pri uresničevanju kanadskih interesov, kot pa ponuja odgovorov.

Doseganje nacionalnega konsenza glede vloge oboroženih sil obeh proučevanih držav ovira zmanjševanje vedenja o vojaških zadevah med civilnim prebivalstvom, tako med politiko kot med splošnim prebivalstvom. Kot drugi ovirajoč dejavnik pa je po mnenju avtorjev mogoče identificirati zmanjševanje števila ljudi z neposrednimi vojaškimi izkušnjami (Winslow in Dandeker, 2000, 7). Zmanjševanje civilnega vedenja o vojaških zadevah pa se zrcali v odporu številnih vojaških oseb do politike in političnih vprašanj.

Ob upoštevanju trendov sprememb v vojaških organizacijah je mogoče povleči vzporednice z organizacijami zasebnega sektorja. Po mnenju Dandekerja (glej Winslow in Dandeker, 2000, 9) je treba biti pozoren na šest razsežnosti. Kot prva, konec neposredne grožnje nacionalni ozemeljski suverenosti je vzporeden z odsotnostjo stabilnega trga za podjetja. Kot druga, vojaške ureditve, na primer v Veliki Britaniji in Kanadi, so dosegle najnižjo stopnjo od druge svetovne vojne. Zmanjševanje velikosti podjetij od osemdesetih let 20. stoletja je vzporedno s tem procesom. Tretja, oborožene sile se spoprijemajo s celo vrsto nalog, ki obsegajo predvsem nevojne operacije pri zagotavljanju mednarodne varnosti. V civilnem svetu pa so se podjetja prisiljena prilagajati zahtevam globalnih trgov. Četrta, oborožene sile so se prisiljene spoprijemati z možnostjo prenašanja poslovnih modelov na vojaško okolje, kar je tudi odraz prestrukturiranja civilnih podjetij. Peta, vojaške in civilne organizacije se morajo spoprijeti s kulturnimi in družbenimi izzivi spreminjajoče se družbe. Šesta, oba tipa organizacij želita na najboljši način izrabiti prednosti sodobnih tehnologij, da bi dosegla prednost pred tekmeci. Vse te razsežnosti je po mnenju avtorjev mogoče opazovati tako v kanadskih kot v britanskih oboroženih silah ter v njihovem odnosu do civilnega okolja. 
Po mnenju Dandekerja (glej Winslow in Dandeker, 2000, 16) obstaja nevarnost, da pragmatični vidik povzroči napačno zaznavo, da je izpolnjevanje funkcionalnih in socialnih imperativov za oborožene sile igra ničelne vsote. Oborožene sile se srečujejo s številnimi izzivi za njihovo svojevrstno kulturo. Morajo razviti osebno strategijo, ki ne bo ogrozila njihove operativne učinkovitosti. V zdravih demokracijah pa je nujno, da oborožene sile niso preveč oddaljene od družbe, ki jo branijo.

Verjetno najzanimivejše delo Donne Winslow s področja vojaške kulture je bilo njeno proučevanje obredov prehoda in povezovalnih obredov v kanadskih oboroženih silah oziroma v njihovem padalskem regimentu (Winslow, 1999). Raziskavo je spodbudil dogodek v kanadski javnosti januarja 1995, ko so v javnost prišli šokantni posnetki poniževalnih in nagnusnih obredov prehoda $\mathrm{v}$ enoti kanadskega padalskega regimenta (Canadian Airborne Regiment). Avtorica se v svojem članku ukvarja $\mathrm{z}$ vprašanjem vzpostavljanja povezanosti $\mathrm{v}$ primarnih skupinah in o uporabi nekonvencionalnih metod za krepitev kohezivnosti enote. Kot tehnična svetovalka je sodelovala v preiskovalni komisiji, ki je proučevala dejanja kanadskih pripadnikov sil OZN v Somaliji (Commision of Inquiry into the Deployment of Canadian Forces to Somalia), in je pričala pred kanadskim parlamentom, vendar končno poročilo te komisije ni dostopno javnosti. Nekaj avtoričinih izsledkov o vedenju pripadnikov padalskega regimenta in vzrokih za tako vedenje je mogoče izluščiti iz članka. Nedvomno so k tako krutim obredom prehoda, v katerih je bilo sodelovanje izključno prostovoljno, prispevale svojevrstnost padalske enote, struktura in organizacijska uvrstitev v širšo strukturo kanadskih oboroženih sil. Narava dela v padalski enoti je takšna, da je treba brezpogojno zaupati v sovojaka in obredi prehoda in iniciacije so bili vsebinsko zasnovani tako, da so dokazovali to zaupanje z različnimi nekonvencionalnimi metodami, ki so temeljile na osebnem psihičnem in fizičnem poniževanju. Zanimivo je razmišljanje vojakov, ki so sodelovali v obredih, da jim ni žal oziroma da so izjemno ponosni, da so preživeli obrede, ampak da jim je žal, da so posnetki prišli v javnost (glej Winslow, 1999). Avtorica ugotavlja, da čeprav sta skupinska zvestoba in povezanost v času boja pomembni, pa lahko povezovanje manjših skupin povzroči in krepi pojav neprimernih norm (Winslow, 1999, 453). Pri tem navaja Janowitza, da primarne skupine, ki so visoko kohezivne, lahko ogrozijo cilje vojaške organizacije, ker predstavljajo neformalna omrežja. Skupinska povezanost lahko predstavlja grožnjo legitimnosti avtoritete ali pa spodkoplje disciplino, ko skupina postane sama sebi najpomembnejša, pomembnejša od same vojaške organizacije.

\subsection{Afera v Somaliji in vprašanje pretirane zvestobe sovojakom in enoti}

Verjetno je Donna Winslow tudi najbolj poznana po že omenjenem proučevanju kontingenta vojakov iz Canadian Airborne Regiment v mirovni misiji v Somaliji leta 1993. Kontingent (Canadian Airborne Regiment Battle Group) je na misijo v Somalijo prišel decembra 1992. Marca 1993 je v njem prišlo do več incidentov: vojaki so streljali na Somalce, ki so vdirali na območje vojaške baze, do smrti pretepli somalskega najstnika Shidana Aroneja v prostoru vojaškega pripora, eden od teh 
vojakov je poskušal storiti samomor (pri čemer je utrpel resne poškodbe možganov). Po misiji so ključne informacije domnevno zadrževali ali spreminjali, v javnost pa so prišli tudi posnetki šikaniranja med pripadniki tega kanadskega polka (Winslow, 2003a). Leta 1995 so polk ukinili. Tistega leta je kanadska vlada po močnih pritiskih parlamenta, medijev in javnosti ustanovila neodvisno preiskovalno komisijo. Ta je razkrila pomanjkljivosti, in protislovja $v$ vojaški organizaciji in vojaškem vodenju, pokazala pa tudi na težave, ki jih ima parlament na področju civilnega nadzora nad oboroženimi silami (Winslow, Klep, 2004).

Donna Winslow je ugotovitve preiskovalne komisije večkrat uporabila kot izhodišče za druge analize. Tako sta s Christom Klepom na primeru afere v Somaliji analizirala vlogo in delo kanadskega parlamenta na obrambno-varnostnem področju. Kot ugotavljata, sta parlamentarni nadzor in javni interes na obrambnem področju v kanadskem političnem sistemu šibka. Na primeru afere v Somaliji se je ta šibkost pretvorila, ne toliko v boj med vlado in parlamentom, temveč v boj med vlado in preiskovalno komisijo (Winslow, Klep 2004, 3). Zdi se, da prispevek med drugim opozarja na že skoraj nemoč preiskovalnih komisij in politična obračunavanja. Druge vojaške komisije so namreč ugotovile, da so težave v izobrazbi častnikov in nedoločni vlogi rezerve. Zato so se v kanadski vojski odločili, da se bodo odpravljanja težav lotili z reformo vojske.

Ob razkritih nepravilnostih v mirovnih operacijah je Donno Winslow zanimalo, kaj je vzrok razpada discipline. Obravnavala je primera disciplinskih vprašanj v kanadskih kontingentih v Somaliji (december 1992-maj 1993) ter Bosni in Hercegovini (oktober 1993-maj 1994). Incidentov namreč niso odkrili le med misijo v Somaliji, temveč tudi med misijo v Bosni in Hercegovini, kjer so opazili zlorabe alkohola, spolne zlorabe, neposlušnost, nasilje in črnoborzijanstvo. Donna Winslow je poskušala ugotoviti, ali je vzrok za take in podobne incidente mogoče najti v vojaški kulturi. Solidarnost, privrženost narodu, vojski in tovarišem oziroma skupini, boj za tovariša $\mathrm{v}$ boju ipd. so institucionalne vrednote, ki so v vojski izredno pomembne. Imajo zlasti motivacijsko vlogo, pomagajo pa tudi pri spopadanju z bojnim stresom, kar je Stouffer ugotavljal že v raziskavi med drugo svetovno vojno. Raziskovalci (Brotz in Wilson, 1946, po Winslow, 2004, 5) so pa kar kmalu zaznali tudi negativne učinke močnega povezovanja vojakov. Lahko namreč pripelje do prikrivanja neprimernega ravnanja sovojakov in upiranja, da bi sovojake predali preiskovalcem. Skupinska povezanost je torej dvorezni meč (Winslow, 2004, 1-5).

Polkovni sistem, ki so ga tradicionalno gojili v Kanadi, pomeni veliko samostojnost vojaške enote. Taka enota ni vpeta v klasičnem smislu v poveljevalno verigo, saj enota svoje pripadnike sama kadruje, usposablja ipd. V takih enotah se lahko razvijejo tudi skrajne oblike iniciacije, kar tudi opisuje Donna Winslow (1999, 2004). Močna povezanost je najbrž eden od razlogov, da se kanadski vojaki ob preiskavi afere v Somaliji in šikaniranja v enoti »niso spomnili podrobnosti«, da je v enoti vladal tak pritisk, da sta »prav in narobe izgubila svoj pomen«, da so se vojaki obdali z »zidom molka«. Solidarnost v taki enoti pomeni kodeks vedenja, je nekaj, 
o čemer se pripadnik ne sprašuje. Vsakega, ki bi kršil notranje norme povezanosti, pa bi doletela ostra kazen. Pretirana zvestoba sovojakom in enoti pa, kot ugotavlja Donna Winslow na primeru kanadske enote, lahko pripelje do obstrukcije, kar ovira ustrezno preiskavo kriminalnih dejanj (Winslow, 2004, 5-13).

\section{RAZLIČNOST V OBOROŽENIH SILAH}

Med pomembna raziskovalna področja Donne Winslow spada proučevanje različnosti v oboroženih silah. Donna Winslow je soavtorica poglavja o različnosti v oboroženih silah (2003) skupaj z Lindy Heinecken in Josephom L. Soetersom. Avtorji ugotavljajo, da sodobne oborožene sile postajajo vedno bolj notranje različne, kar zadeva etničnost, spol in religije, to pa je dejansko posledica številnih dejavnikov. Med drugim tudi zaradi prehoda od naborniških $\mathrm{k}$ popolnoma prostovoljnim poklicnim oboroženim silam. Tudi civilne družbe so etnično bolj raznovrstne, kot so bile, kar se nedvomno kaže tudi na notranji strukturi oboroženih sil, to pa povzroči vprašanja enakih zaposlitvenih možnosti za pripadnike vseh družbenih skupin in slojev. Poglavje v Handbook of the Sociology of the Military se ukvarja z vprašanji različnosti v neameriških oboroženih silah in ponudi pregled izzivov, s katerimi se spoprijemajo oborožene sile držav po svetu, na posameznih primerih iz Kanade, Zahodne Evrope in Južne Afrike. Poglavje se osredotoči tudi na vprašanje različnosti v novih varnostnih operacijah oziroma v mirovnih operacijah ter se dotakne odnosa z lokalnim prebivalstvom in drugimi (vojaškimi) organizacijami v smislu kulturne povezljivosti.

Donna Winslow je bila tudi avtorica študijskega gradiva za seminar o vprašanjih spola v vojaški sociologiji, ki ga je predavala na švedski Kraljevi vojaški akademiji. V študijskem gradivu opozori na pomen institucionalno poklicnega modela Morrisa Janowitza v vojaški sociologiji in v luči tega modela opozori na vprašanje integracije žensk v oborožene sile. Na kratko obravnava načelo enakosti med spoloma ter ponudi pregled temeljnih mednarodnih dokumentov s tega področja, okrepljeno pozornost pa posveti vsebini resolucije Varnostnega sveta OZN 1325. Poleg te resolucije pa kot enega najpomembnejših dokumentov o človekovih pravicah žensk navede Konvencijo o odpravi vseh oblik diskriminacije do žensk iz leta 1979, ki ima status pravno obvezujočega sporazuma. Avtorica kritično oceni vlogo Organizacije združenih narodov na področju doseganja enakosti med spoloma. Na koncu opozori, da načelo enakosti med spoloma ni samo vprašanje žensk in deklet. Eno od vprašanj koncepta spola je, po njenem mnenju, v tem, da je tako kot koncept etničnosti prepogosto identificiran z biološko danostjo. Pa vendar je spolna identiteta, tako kot etnična identiteta, konstruirana v dinamičnem socialnem okolju. Ob tem pa ugotavlja prisotnost še mnogih izzivov, odsotnost usklajevanja, nadzora in spremljanja v povezavi z uresničevanjem načela enakosti med spoloma, kljub obstoju številnih iniciativ. Pomen gradiva, ki ga je Donna Winslow pripravila za seminar na švedski Kraljevi vojaški akademiji, je v vsebini in seznamu izbrane bibliografije s področja razlikovanja med spoloma na splošno in v oboroženih silah. 
Donna Winslow je svoje zanimanje za vprašanje spola v oboroženih silah uresničila tudi na proučevanju žensk v kanadskih oboroženih silah in o tem tudi objavila vsaj en članek v reviji Current Sociology (2002a). Kanadske ženske imajo dolgo tradicijo sodelovanja v oboroženih silah in boju, bile so vojne ujetnice, vohunke, obveščevalke, pa vendar nikoli v zgodovini niso uradno sodelovale $\mathrm{v}$ boju kot bojevnice $\mathrm{v}$ jurišnih enotah. In ravno to vprašanje zakonite vključenosti žensk v bojne enote kanadskih oboroženih sil je v ospredju tega članka. Avtorica se osredotoči na vprašanje integracije žensk v kanadske oborožene sile, pri tem pa opozori na dvodelnost integracije. Najprej so to zakonski standardi, ki omogočajo vključenost žensk, po kanadski zakonodaji imajo moški in ženske enake možnosti dostopa do vseh enot kanadskih oboroženih sil in diskriminacija po spolu ne obstaja (Winslow, 2002a, 642). Druga integracija pa je družbene narave, ki pa je veliko širša od vprašanja zakonsko dovoljenega vstopa $\mathrm{v}$ bojne enote. Avtorica gradi na trditvi, da so bojne enote veliko bolj »odmaknjene« od civilne družbe kot druge enote kanadskih oboroženih sil, posledično pa izpostavljajo tradicionalno moške vrednote, predvsem moški model bojevnika, s čimer nasprotujejo integraciji žensk. V članku predstavi integracijo žensk v kanadske oborožene sile, najprej z notranjega zornega kota, torej z vidika oboroženih sil. Hkrati s tem pa predstavi, kateri so tisti dejavniki, ki so prihajali iz zunanjega (civilnega) okolja in ki so imeli spodbujevalni učinek na integracijo žensk v kanadske oborožene sile. Članek sklene z identifikacijo nekaterih vprašanj, ki jih kanadske oborožene sile še vedno morajo rešiti oziroma morajo nanj poiskati odgovore, če želijo uspešno odgovoriti na izzive integracije žensk. Kot na primer koliko časa lahko noseča pripadnica dela v oboroženih silah. Z vstopanjem žensk v bojne enote je mogoče pričakovati povečano število »dvojnih« parov, tj. parov, v katerih sta partner in partnerica pripadnika oboroženih sil. Kako bodo poveljniki vojnih enot reševali vprašanje takih parov? Kako se bodo reševala vprašanja pošiljanja v misije, ko so ženske matere samohranilke? Avtorica ugotavlja, da bo v luči novih izzivov treba prevetriti politiko skrbi za družine pripadnikov oboroženih sil. Kljub dejstvu, da imajo ženske dovoljen vstop v bojne enote kanadskih oboroženih sil že od leta 1989, ostaja še precej vprašanj nerešenih in še vedno se spoprijemajo s številnimi ovirami, ki so ukoreninjene v negativnih stališčih moških kolegov, ki še verjamejo, da je bojevanje izključno domena moških.

\section{MIROVNE OPERACIJE: IZZIVI POVELJNIKOV NA MISIJI, TEŽAVNOST ODNOSA MED NEVLADNIMI ORGANIZACIJAMI IN VOJSKO}

Izkušnje terenskega raziskovanja so za raziskovalca velikega pomena. Donna Winslow je tako med drugim proučevala življenje in delovanje kanadskih vojakov v mirovni operaciji v Bosni in Hercegovini. Na raziskovalnem obisku je bila oktobra 1998, kjer je intervjuvala vojake. Njen prispevek v knjigi The Human Command: Peace Support Operations izhaja iz teh intervjujev, pa tudi iz drugih raziskav in študij (Winslow, 2003b, 174-175). Zanimiv je zlasti zato, ker splošne ugotovitve o življenju in delovanju vojske v mirovni operaciji predstavi skozi sito ravnanja vojaških poveljnikov na operaciji. Kakšni so po znanstveni presoji Donne Winslow 
poveljniški izzivi v mirovnih operacijah: ustvarjanje zdravega ravnotežja med prostim časom in organiziranimi dejavnostmi na misiji; večanje odgovornosti častnikov na nižjih hierarhičnih ravneh; motiviranje vojakov (kako motivirati vojake, ko misija ni pustolovščina, temveč je dolgočasna, in ko ni dovolj denarja, zaradi katerega bi vojaki ostali na misiji in v vojski); visok operativni tempo; povezljivost (izziva sta na primer ohranjati lastne standarde in biti hkrati »timski igralec«, narediti kohezivne sile iz sestavin z neenakimi viri); ohranjanje nepristranskosti v zahtevnem in včasih sovražnem okolju, zagotoviti, da bodo vojaki razumeli, da lahko imajo prijaznost in darila domačinov prikrite motive; v odnosu do nevladnih organizacij preiti ovire, ki jih lahko postavljajo starostne, spolne in rasne razlike in razlike v organizacijski kulturi; poveljniki morajo razumeti organizacijske razlike med vojsko in nevladnimi organizacijami, ki bi lahko vplivale na komunikacijo in zmožnost za sodelovanje; omogočiti, da vojaki razumejo, da lahko imajo njihova dejanja na misijah daljnosežne posledice (že zaradi medijev oziroma njihovega poročanja). Zelo resen izziv poveljnikom na misijah je tudi slaba povezanost med poveljstvom doma in kontingentom na misiji oziroma že kar nezaupanje ali strah, da poveljstvo oziroma vojaški vrh ne bo podprl odločitev poveljnikov na misiji (npr. nepodpora, če je na misiji ustreljen civilist). Med izzivi je tudi odgovor na vprašanje, kakšno naj bo usposabljanje, ki bo kar najbolj ustrezno pripravilo vojake na misijo. Donna Winslow iz pogovorov Z vojaki in častniki ugotavlja, da je bilo sodelovanje pri pomoči ob ledenem viharju v Kanadi najboljše mogoče usposabljanje za operacijo (Winslow, 2003b, 175-188).

Pomemben prispevek k vedenju o mirovnih operacijah predstavljajo analize odnosov med vojaškimi in nevojaškimi udeleženci na območju operacije. Med njimi namreč velikokrat nastaja napetost ali pa vsaj nerazumevanje in s tem poslabšanje komunikacije, usklajenosti in sodelovanja. Zapleteni so zlasti odnosi med vojaškimi strukturami in nevladnimi organizacijami, ki zagotavljajo humanitarno pomoč. Te problematike se je lotila tudi Donna Winslow in pripravila pregled mogočih napetosti med obema vrstama struktur, pri čemer je, kot običajno, izhajala iz lastnega raziskovanja in ugotovitev drugih študij. Identificirala je pet točk mogočih napetosti, in sicer: organizacijska struktura in kultura, naloge in način izpolnjevanja nalog, definicije uspeha in časovnih okvirov, zmožnosti za uveljavitev vpliva na nadzor nad informacijami in nadzor nad viri. Teh pet točk skupaj imenuje »model kulturne povezljivosti« (Winslow, 2002b).

$\mathrm{Na}$ točki organizacijske strukture in kulture tako pri nevladnih organizacijah kot pri vojski nastaja medsebojno nezaupanje in strah pred izgubo lastne identitete pri sodelovanju obeh struktur. Včasih se pripadniki nevladnih organizacij in vojske gledajo postrani že zaradi motivov, zakaj so na misiji. Medtem ko so vojaki na misiji po ukazu, poleg opravljanja dolžnosti pa jih najpogosteje motivira le še denar, so »nevladniki« prostovoljci, ki se morajo za izpolnjevanje svojih altruističnih ciljev včasih tudi čemu odpovedati. Praviloma imajo slednji na misiji manj udobja in varnosti kot vojaki, ki so nastanjeni v utrjenih in opremljenih bazah. Zaradi vsega tega se imajo, kot se zdi, »nevladniki« za nekaj več od vojakov. Med vojaško in nevladnimi strukturami so tudi razlike glede hierarhije in (de)centraliziranosti odločanja ter razlike 
v spolni in etnični strukturi. Te razlike lahko povzročijo težave v komunikaciji med ljudmi iz obeh struktur.

Pri nalogah in načinu njihovega izpolnjevanja avtorica opozarja na težave, kot so strah nevladnih organizacij pred povezovanjem z vojsko zaradi posledično mogoče večje ogroženosti (primer nemirov v Drvarju v Bosni in Hercegovini, ko so bile napadene tudi nevladne organizacije) in nevarnosti, da ostanejo nezaščitene, kadar bo vojska odšla na bolj vojaške naloge. Vojaške strukture na misiji in nevladne organizacije se pogosto razlikujejo tudi v različnem razumevanju strateškega cilja misije.

Glede definiranja uspeha in časovnih okvirov Donna Winslow piše o različnih razumevanjih uspeha mirovne operacije pri različnih udeležencih. Tako je za nevladne organizacije uspeh zmanjšati trpljenje ljudi, za javno mnenje in medije je uspeh konec bojevanja, za nacionalno politiko je ključno, da ni več žrtev med domačim prebivalstvom in da se izboljša ugled nacionalne vlade, za vojsko pa je uspeh izpolnitev njene naloge. Pri vojski, zlasti pri vojaških poveljnikih, je običajno ključno tudi to, da se misija konča brez žrtev med njihovimi vojaki. Včasih se temu cilju podredi celo mandat - bolje je, da se mandat v celoti ne izpolni, kot pa da so med vojaki žrtve.

Problematično za sodelovanje vojaških in civilnih nevladnih struktur je tudi, da imajo te strukture različna obdobja razmestitve. Tako se vojaški kontingenti menjavajo na pol leta ali celo pogosteje, ljudje v civilnih strukturah pa ostajajo na misiji dlje časa, tudi po več let.

Večkrat imajo različne strukture tudi različne poglede na to, kaj je v nekem obdobju misije pomembnejše. Praviloma so na začetku cilji varnostni, dolgoročno pa mora biti delovanje usmerjeno v ekonomsko obnovo, izobraževanje in razvoj. Če razumevanje ciljev glede na obdobja ni enotno, lahko tudi to povzroči napetosti med različnimi strukturami na misiji.

Velika nevarnost za misijo pa je tudi, da ni opredelitve, kaj je končno stanje, ko se misija konča, mednarodne strukture pa se umaknejo. Je končno stanje konec sovražnosti ali gre za humanitarno definicijo v smislu, da na območju misije ni več potreb po humanitarni pomoči?

Pri zmožnosti za uveljavitev vpliva na nadzor nad informacijami Donna Winslow ugotavlja, da so vojska, nevladne organizacije in mediji pri tem v neenakem položaju, saj lahko slednja svoj vpliv širita tudi v mednarodnem prostoru in imata boljše možnosti dostopa do strani v sporu in nacionalnih vlad. To včasih tudi izkoriščata za pridobitev večjega vpliva in boljše financiranje. Brez javne predstavitve nevladnih organizacij in njihovega dela, običajno s pomočjo medijev, je finančna podpora tem organizacijam vprašljiva. Zaradi take prakse lahko začnejo nevladne organizacije med seboj tekmovati za medijsko pokritje. Tako so za medijsko pokritje pripravljene, da gredo $\mathrm{v}$ zelo tvegane razmere in da delo opravljajo same. Ker vojaška prisotnost na nekem 
območju običajno pritegne politično in medijsko pozornost, imajo od tega koristi tudi nevladne organizacije, pri čemer pa se oboji bojijo negativnega poročanja o sebi. Za vojsko to namreč lahko pomeni konec karier posameznikov, za nevladne organizacije pa prenehanje financiranja. Medsebojni interes imajo vojaške in nevladne strukture tudi pri informacijah, ki so na misijah ključnega pomena. Težave lahko nastanejo, kadar ena od struktur daje drugi informacije, druga prvi pa ne.

Pri nadzoru nad viri je ključna ugotovitev, da organizacije na območju misije tekmujejo za viri. Nevladne organizacije tekmujejo med seboj za financiranje, opremo, pa tudi območja delovanja. Vojska ima najrazličnejše zmogljivosti in jih nevladnim organizacijam pogosto tudi daje na razpolago. Vendar nevladne organizacije vojaških zmogljivosti vedno ne želijo uporabljati. Zlasti ne tedaj, ko se iste vojaške zmogljivosti, ki bi jih uporabili v humanitarne namene, uporabljajo tudi v operacijah vsiljevanja miru. Včasih pa se vojaške strukture počutijo že kar izkoriščane, saj pravijo, da nimajo dovolj zmogljivosti, da bi hkrati izpolnile humanitarne in vojaške potrebe. Zanimivo pa je tudi, da nevladne organizacije včasih želijo uporabiti vojake kot vir oziroma sredstvo, da bi ljudem razdeljevale svojo humanitarno pomoč (povzeto po Winslow, 2003b).

Kdo je torej v razmerjih med vojsko in nevladnimi organizacijami »čuden« (Donna Winslow uporabi besedno zvezo »strange bedfellow«)? Pravzaprav obe strukturi. Kljub temu pa morata na misijah ostajati skupaj, saj se njune naloge pogosto prekrivajo. Posamični ukrepi za izboljšanje sodelovanja občasno celo obrodijo sadove. Tako se poskuša izboljšati medsebojno razumevanje z izmenjevanjem ljudi, izboljša se usklajenost delovanja, kadar ena od organizacij prevzame usklajevalno vlogo (primer kanadske vojske na Kosovu), za izboljšanje komunikacije se razmišlja o skupnih sedežih vodstev.

\section{KANADSKA VOJSKA V VARNOSTNEM OKOLJU 21. STOLETJA}

Leta 2000 je Univerza v Ottawi organizirala konferenco z naslovom »Kanadske posebnosti v 21. stoletju«, na kateri je Donna Winslow sodelovala s prispevkom o kanadski vojski. Dvojezični zbornik prispevkov je izšel tri leta pozneje. Žal se je varnostno okolje $\mathrm{v}$ vmesnem času zaradi 11. septembra izrazito spremenilo, čemur pa se prispevki v zborniku, kot ugotavlja Belanger (2005), niso prilagodili. Kritik Belanger sicer prispevek Donne Winslow pohvali, saj je bila avtorica dokaj izzivalna, ko je pisala o paradoksu, da je kanadska družba zelo sentimentalna do mirovnih misij, ki jih izvaja kanadska vojska, hkrati pa vztrajno nasprotuje virom, ki so nujni za misije. Kot piše Donna Winslow (2003c), Kanada dejansko tradicionalno goji podobo mirovnika. Sodelovanje kanadske vojske v mirovnih operacijah se dobro pokriva s kanadsko zunanjo politiko (zlasti zavezanost Združenim narodom) in konceptom Kanade kot srednje velike sile. Kanada v svetu tako nastopa kot neodvisen suveren udeleženec, kar ji prinaša ugled. Kljub vključenosti v mirovne operacije pa Kanadčani svoje vojske ne vidijo kot pomembno nacionalno institucijo in ne podpirajo obrambnih izdatkov. Posledično zmanjševanje zmogljivosti sil pa vpliva tudi na zmanjševanje avtonomije in vloge Kanade v mednarodni varnostni 
politiki. Z zmanjševanjem obrambnega proračuna, kar povzroča izgubo zmogljivosti »trde moči«, sovpada tudi premik kanadske zunanje politike k »mehki moči«.

Iz prispevka tudi vidimo, da je avtorica na začetku 21. stoletja že razpoznavala pomembne spremembe, ki so temeljne lastnosti današnjega varnostnega okolja oziroma po 11. septembru 2001. Tako ugotavlja, da bodo sodobni konflikti mešanica visoke in nizke tehnologije, da bodo žrtve, vojaške in civilne, pomembno politično vprašanje, da bodo $\mathrm{v}$ operacijah pomembni številni nevojaški udeleženci, da bo pravo (pravno svetovanje) postalo sestavni del vojaških dejavnosti, da bodo kibernetski napadi postali pomembna grožnja in da se bo spremenila podoba sovražnika (kriminal, velika krutost) (Winslow, 2003c).

Na nacionalni ravni ugotavlja, da se bo vojska morala prilagoditi večjemu individualizmu, egalitarnosti in pravdarstvu v družbi, da bo občutila zmanjševanje spoštovanja do avtoritet ter iskanja pravice zunaj formalnih poveljevalnih poti in da bodo povezave med vojsko in družbo slabele. Slabljenje povezav pa bo izhajalo iz nepoznavanja vojske med politiki in iz vedno slabše družbene reprezentativnosti vojske. Za premostitev tega predlaga, da se krepi podporna povezanost vojske in družbe. Le tako bomo imeli zdravo demokracijo (Winslow, 2003c).

\section{VARNOSTNA RAZSEŽNOST GLOBALIZACIJE: OD NOVIH RAZSEŽNOSTI KONFLIKTOV DO KONCEPTA ČLOVEKOVE VARNOSTI}

Obdobje globalizacije je zagotovo ena največjih revolucij v človeški zgodovini, saj so se praktično spremenile vse ravni človekovega ravnanja in obstoja, od ekonomskih, političnih, tehnoloških, socialnih in navsezadnje do varnostnih dejavnikov. Čeprav se je v prvem obdobju zdelo, da bo globalizacija predstavljala predvsem pot v globalno sodelovanje (globalno vas), pa je kaj hitro postalo jasno, da se z njo začenja tudi novo obdobje konfliktov in spopadov, ki ne bodo nič manj krvavi in okrutni, kot so bili v preteklosti. Postali pa so bistveno bolj zapleteni in razpršeni, zato je bila velika sprememba nujna tudi na teoretično-analitičnem področju. Le tako je bilo mogoče razumeti nova dogajanja v svetu in brez dvoma je bila Donna Winslow ena najpronicljivejših avtorjev, ki so razumeli nove varnostne in analitične koncepte, še več, tudi soustvarjala jih je. Pri tem je izredno dobro kombinirala svoja antropološka, zgodovinska, vojaško-sociološka in seveda tudi varnostna znanja. S tem je nakazala, da bo mogoče sodobna dogajanja pojasniti zgolj na znanstveno raznovrstni in večdisciplinarni način. Zato bomo v nadaljevanju predstavili nekatera dela, ki kažejo, kako je razumela sodobne zamisli, kot so globalna, državna in človekova varnost, seveda pa se ne moremo izogniti niti njeni analizi globalizacijskih procesov, ki so spremenili naše zaznavanje sveta. In navsezadnje je bila empirična analiza konfliktov, kot sta primera Balkana in Kavkaza, samo povod, ki je avtorico navdihnil k spremenjenim teoretičnim zamislim in izhodiščem. 
Čeprav se morda tega dejstva niti ne zavedamo, pa je novo razsežnost svetovnih konfliktov nakazal že konflikt na Kavkazu, natančneje v Čečeniji. Večina ljudi, predvsem na Zahodu, je sicer sprva mislila, da gre za še en primer lokalnih konfliktov, ki prevladujejo že vse od konca druge svetovne vojne, vendar pa so naftna politika, begunski tokovi, mednarodne kriminalne združbe, vpletenost mednarodnega islamskega radikalizma, katerega duhovni vodja je bil Osama bin Laden, vloga medijev in nevladnih organizacij ter seveda splet pokazali, da gre v bistvu za konflikt na mednarodni ravni oziroma globalizirani konflikt. Svetovni splet mednarodnih organizacij, diaspor, mednarodnih terorističnih mrež in seveda globalnih medijev na čelu s spletom je namreč lokalnim udeležencem omogočil, da so svoja vprašanja, interese in seveda tudi konflikte kolikor mogoče internacionalizirali ter prešli nacionalne in državne meje konfliktov (Kloos v Winslow in Moelker, 2002). In ravno to je eno od glavnih izhodišč analize konfliktov po hladni vojni. Globalizacija je namreč proizvedla globalno kulturo, po drugi strani pa ljudje še vedno (seveda fizično) delujejo v lokalnem okolju. Tako je mogoče doseči lokalne cilje in razvoj identitete s pomočjo globalnih tehnologij in udeležencev (Winslow in Moelker, 2002). Spoj globalnega in lokalnega pa je tisti, ki najbolj ogroža vmesni člen, to je nacionalno državo. V tem kontekstu lahko razumemo tudi razvoj koncepta človekove varnosti, ki je v aplikativnem smislu ravno nacionalni državi povzročil precej težav, saj je zamajal temelje vestfalske ureditve mednarodnih odnosov, katerih središče je še vedno suverena država. Uporniške skupine, kot kaže tudi primer iz Čečenije, so torej lahko transnacionalne komunikacijske infrastrukture uporabile za poudarjanje svoje kulturne posebnosti in navsezadnje za boj za neodvisnost. Seveda lahko tukaj govorimo o »globalizaciji od spodaj«, ko lokalni udeleženci izkoriščajo njene pridobitve, prav tako pa avtorja izpostavita tudi »globalizacijo od zgoraj«, ko so transnacionalne komunikacijske strukture in mednarodni politični ter ekonomski interesi vplivali na konflikt v Čečeniji.

Globalizacija od zgoraj se v čečenskem konfliktu najprej kaže v geostrateškem pomenu, saj je to območje bogato $\mathrm{z}$ nafto in zemeljskim plinom. Tako Gökay (v Winslow in Moelker, 2002) utemeljuje turško podporo čečenskim upornikom ravno s turškimi geostrateškimi energetskimi načrti, ki so v tej regiji vse prej kot skladni z ruskimi. Medtem ko si je Turčija že ves čas po razpadu Sovjetske zveze prizadevala, da zapolni varnostni vakuum in postane regionalna sila, pa po drugi strani Rusija poskuša ohraniti svoj položaj tako znotraj svojih mednarodno priznanih meja kot v kavkaških in srednjeazijskih državah, ki so nastale na ozemlju nekdanje Sovjetske zveze. Glede na dejstvo, da so se nekatere države začele oddaljevati od Rusije (kot npr. Gruzija), po drugi strani pa so čečenski uporniki postopoma poskušali razširiti svoje delovanje tudi na območje Dagestana, je povsem jasno, da so s tem ogrozili ruske geostrateške energetske načrte. Silovit odgovor Rusije je bil samo vprašanje časa. Seveda pa naftno vprašanje ni edini globalizacijski učinek od zgoraj, ki je vplival na rusko-čečenski konflikt. Množični mediji in javno mnenje so gotovo tisti element, brez katerega konflikta med globalizacijo preprosto ni več mogoče dobiti. Zato si seveda vse strani prizadevajo dobiti ta informacijski spopad. Thomas (v Winslow in Moelker, 2002) je tako pravilno ugotovil, da so tako Rusi v vojni s 
Čečeni leta 1995 informacijsko oziroma propagandno vojno povsem izgubili (celo v Rusiji so potekali protivojni protesti, ki so primerjali Čečenijo z afganistansko katastrofo, prav tako so matere vojakov protestirale celo v Groznem (Duk v Winslow in Moelker, 2002), druga čečensko-ruska vojna pa je bila povsem nekaj drugega. V tej so Rusi zmagali že od prvega dne spopadov. Ruska vojska se je namreč povsem zavedala, da mora najprej dobiti informacijsko vojno in šele tej bo lahko sledila zmaga tudi na bojišču. Tako so Rusi po zgledu Američanov iz zalivske vojne v letih 1990-1991 takoj povabili mednarodne novinarje in oblikovali novinarske »poole «, ki so poročali natančno tisto, kar so Rusi želeli (Westerman v Winslow in Moelker, 2002). V tej informacijski kampanji pa so Rusom izdatno pomagali tudi sami Čečeni, saj so se iz borcev za svobodo spremenili v teroriste. Povsem napačno so začeli delovati zunaj Čečenije tako v Dagestanu kot drugih delih Ruske federacije, in če je leta 1995 kar 76 odstotkov Rusov podpiralo čečenske težnje po neodvisnosti, je leta 1999 več kot 60 odstotkov podpiralo vojaško posredovanje, ki naj bi preprečilo čečensko odcepitev (Pain v Winslow in Moelker, 2002).

Nadaljnji, zelo pomemben element globalizacije od zgoraj pa je mednarodna skupnost. Konflikt v Čečeniji je bil namreč že od samega začetka podobno kot v Jugoslaviji predmet razprav v okviru mednarodnega prava in pravnega koncepta ius gentium, ki je korpus norm materialnega in formalnega prava nekega naroda. Čeprav mednarodno pravo seveda daje prednost suvereni državi (v tem primeru Ruski federaciji), Čečeni pa v tem okviru nimajo formalne pravice do odcepitve, so nekatera mnenja že nakazovala spremenjene pristope. Tako je nekdanji nizozemski zunanji minister Kooimans izpostavil, da lahko ljudje zahtevajo samostojnost, če jim ni zagotovljena primerna avtonomija oziroma so jim kršene državljanske in človekove pravice. Posredovanje v Somaliji je predstavljalo tak precedens, enako velja za Kosovo. Pri obeh naj bi kršitev državljanskih in človekovih pravic ogrožala mednarodni mir in varnost. Ta pravni in humanitarni argument bi seveda lahko uporabili tudi v Čečeniji, vendar se postavlja vprašanje, katera mednarodna organizacija ga je pripravljena in tudi sposobna uresničiti (Winslow in Moelker, 2002). Mednarodna skupnost je sicer večkrat protestirala zaradi dogajanj v Čečeniji. Do napadov na ZDA 11. septembra 2001 je večina držav izražala nestrinjanje z Rusijo. Indija se ni želela izjasniti, medtem ko je Kitajska odkrito podpirala rusko posredovanje. Bala se je namreč lastnih »Čečenij« v obliki Tajvana, Sinkianga in Tibeta (Smith v Winslow in Moelker, 2002). Po drugi strani pa je bila pod pritiskom nevladnih organizacij, kot so Zdravniki brez meja, Amnesty International, Human Rights Watch, in tudi visokega predstavnika OZN za begunce prisiljena obsoditi predsednika Vladimirja Putina zaradi omejevanja delovanja medijev, kršitev človekovih pravic in neproporcionalne uporabe sile. Vendar pa se je vse to spremenilo z 11. septembrom. Tako je Putin v svojem govoru 25. septembra 2001 v Nemčiji zatrdil, da je čečenski upor prvovrstni primer islamskega fundamentalizma in terorizma, in je zaprosil za večje razumevanje ruskega posredovanja (Erlanger v Winslow in Moelker, 2002). Deli čečenskega upora so in še imajo nedvomno povezavo z islamskim ekstremizmom, seveda pa je zelo zanimivo, kdo, tudi v Čečeniji, stoji za tem gibanjem. Sevunts (v Winslow in Moelker, 2002) tako trdi, da sta glavni čečenski uporniški skupini, ki 
sta ju vodila Šamil Basajev in Emir Khatab, imeli neposredno podporo pakistanske obveščevalne službe ISI, ki je odigrala glavno vlogo pri organizaciji in usposabljanju čečenskih upornikov pri urjenju v Afganistanu. Glede na nekatere vire (Chossudovsky v Winslow in Moelker, 2002) pa je zlasti Khataba podpirala savdska islamska »dobrodelna« organizacija. Čečenski uporniki so imeli torej podporo dveh držav, ki sta glavna ameriška zaveznika v islamskem svetu ...

Zadnja vprašanja - o tem, kakšne so pravice narodov, ki (̌se) nimajo svoje države, kdo in kako bo v spremenjenem mednarodnem varnostnem okolju moral zagotavljati varnost in o naraščanju števila znotrajdržavnih konfliktov - so dokaj jasno izhodišče za koncept človekove varnosti in odnos Donne Winslow do tega področja in bodo predstavljena $\mathrm{v}$ nadaljevanju. Medtem ko je temeljna vprašanja nakazala že avtoričina analiza konflikta v Čečeniji, pa svoje razmišljanje dopolni v konferenčnem poročilu iz leta 2003 (Winslow, 2003d). V njem namreč izpostavi temeljne vzroke, ki so privedli do spremembe definicije varnostnih konceptov. Če je namreč še pred nekaj leti varnost posameznikom najprej morala zagotavljati država, pa se danes pojavlja vse več groženj, na katere država ne more več ustrezno odgovoriti, po drugi strani pa čečenski in tudi kosovski primer dokazujeta, da država lahko celo ogroža varnost svojih državljanov. Hartman (v Winslow, 2003d) tako izpostavlja, da na epidemijo virusa HIV nekatere afriške države niso več sposobne ustrezno odgovoriti, prav tako pa tudi Bellamy in McDonald (v Winslow, 2003d) izpostavljata, da države večkrat predstavljajo vprašanje kot pa rešitev (novih) varnostih izzivov. Avtorica se zato sprašuje, kaj sploh je koncept človekove varnosti in katera so vprašanja njene uvedbe. Vsekakor lahko rečemo, da ima človekova varnost globalne in lokalne razsežnosti, pri tem pa se je avtorica odločila, da bo analizirala nekatere državne pobude (zlasti Japonske in Kanade), pa tudi pobude na mednarodni ravni (v tem okviru je analizirala vlogo OZN pri kolektivni človekovi varnosti).

Ideja človekove varnosti se je prvič pojavila na mednarodni ravni leta 1994 v Human Development Report (UNHDR v Winslow, 2003d), kjer so zelo jasno zapisali, da bo koncept človekove varnosti revolucionarno vplival na družbo 21. stoletja. Argument OZN je namreč bil, da je koncept varnosti preozek in preveč usmerjen v grožnje državi in državni suverenosti. Zato je OZN pozval k širšemu razumevanju varnosti, ki bi se usmerjala na posameznika in skupnost, ne pa na državo. Tako Bruderlein (v Winslow, 2003d) človekovo varnost definira kot priznavanje pomena posameznikovih varnostnih potreb in njihovo izenačevanje v odnosu do državnih, minimiziranje tveganj in sprejemanje preventivnih ukrepov za zmanjšanje človekove ranljivosti. UN Development Report pa je v človekovo varnost umestil preprečevanje groženj, kot so lakota, bolezni in represija (v Winslow, 2003d). Pri tem pa je zlasti pomembno poudariti, da človekova varnost ni enaka človekovemu razvoju, pač pa samo deli konceptualni prostor človekovega razvoja, ki je usmerjen k ljudem in je večrazsežnosten. Človekov razvoj je vsekakor širši, vendar pa je njegov cilj izpopolnitev posameznikov v njihovih domovih in skupnostih (Alkire v Winslow, 2003d). Človekovo varnost pa lahko razumemo kot dopolnitev izbiram v varnem okolju. 
Medtem ko je človekov razvoj dolgoročen, pa človekova varnost vključuje tudi kratkoročne dejavnosti, kot so humanitarna pomoč in mirovne operacije.

Nasprotja med globalnim in lokalnim pa se kažejo tudi pri človekovi varnosti. Kot je UNHDR (v Winslow, 2003) izpostavil že leta 1994, lakota, bolezni, uničevanje okolja, prekupčevanje z mamili, terorizem, etnični spori in družbena dezintegracija že dolgo niso osamljeni dogodki, omejeni z državnimi mejami, pač pa imajo globalne učinke. Po drugi strani pa so ti učinki na človekovo življenje bolj ali manj lokalni. Dejansko so v mnogih razpravah o človekovi varnosti za vse večjo nevarnost okrivili ravno globalizacijo (Canadian Departement of Foreign Affairs and Inernational Trade document v Winslow, 2003d) in njene učinke. Po drugi strani pa so mnogi teoretiki globalizacije (Held v Winslow, 2003d) izpostavili ravno njeno neprecedenčnost, ki bo prisilila vlade in družbe po vsem svetu, da se bodo prilagodile svetu, v katerem že dolgo ni več jasne razmejitve med mednarodnim in domačim, zunanjimi in notranjimi zadevami, prav tako pa nacionalne države niso več edina središča oblasti. Paradigma človekove varnosti je postala po letu 1994 razširjena med različnimi nevladnimi organizacijami in posamezniki, vendar sta dve državi (Kanada in Japonska) izrazito pomembni za promocijo človekove varnosti (v Kanadi je človekova varnost postala celo zunanjepolitična paradigma) (Axworthy v Winslow, 2003d). Čeprav se zdi paradoksalno, da državi postavljata človekovo varnost, ki osnovnega varnostnega objekta ne vidi več v državi, temveč v posamezniku, v ospredje svojega zunanjepolitičnega nastopa, pa je taka državna podpora zelo pomembna, ko gre za operacionalizacijo koncepta človekove varnosti v konkretne politike, ki so na primer povezane z razminiranjem, omejevanjem oziroma prepovedjo protipehotnih min, omejevanjem lahkega strelnega orožja ipd. In seveda je taka podpora pomembna pri razvoju kolektivne človekove varnosti na ravni OZN, čeravno se zdi, da nekateri funkcionarji OZN v svojih poročilih morda delujejo preveč vizionarsko in pogosto pozabljajo, da so osrednji element koncepta OZN še vedno (nacionalne) države. Tako se je termin kolektivne človekove varnosti prvič pojavil v poročilu Boutrosa Boutrosa Ghalija An Agenda for Peace že leta 1992 (v Winslow, 2003d), v katerem je celo zapisano, da je čas za absolutno in ekskluzivno suverenost minil. Koliko to drži, pa lahko presodimo po dvajsetih letih ... Sicer pa moramo priznati, da je Agenda for Peace izpostavila pristop pozitivnega miru, kar pomeni, da mir ni samo odsotnost konflikta, pač pa temelji na socialni pravičnosti in demokraciji. Zato je v tej viziji mir ukoreninjen v človekovi varnosti (Peou v Winslow, 2003d). Njeno nadaljevanje (Brahimijevo poročilo iz leta 2000) pa svoj pristop do kolektivne človekove varnosti utemeljuje na instrumentih »peace makinga« (vzpostavljanje miru z mediacijo in diplomacijo), "peace buildinga« (tvorjenje miru) in »peacekeepinga« (vzdrževanje miru). To poročilo v kontekstu človekove varnosti povsem izpusti vsiljevanje miru (»peace enforcement«) kot vrh mirovnih operacij in ga lahko skladno z avtorizacijo Varnostnega sveta OZN izvedejo koalicije voljnih držav, pri tem pa delujejo skladno s VII. poglavjem Ustanovne listine OZN. Tu pa že lahko opazimo prva naznanila, da bo koncept človekove varnosti še kar nekaj časa bolj ali manj pristop, ki bo imel težave z uveljavljanjem svojih idej. Leto 2001 in revitalizacija nacionalne države ter njene moči po napadih na ZDA pa tako ugotovitev samo podkrepita. In preteči je moralo skoraj deset let, pasti je moralo na tisoče žrtev v vojnah v Iraku in 
Afganistanu, da se je s pojavom Wikileaksa ponovno vzbudil žarek upanja za posameznika, ki bi moral biti osrednji element vsake razprave o varnosti.

\section{6 "HUMAN TERRAIN SYSTEM (HTS)« - ZLORABA DRUŽBOSLOVNE ZNANOSTI V VOJAŠKIH OPERACIJAH?}

Kljub temu da posredovanja ameriških oboroženih sil in njihovih zaveznikov $\mathrm{v}$ Afganistanu in Iraku po letu 2003 niso dobila široke mednarodne podpore (nekatere države so posegom celo odkrito nasprotovale), pa sta ti operaciji zelo spremenili do tedaj veljavna pravila bojevanja, prav tako pa so se spremenili glavni udeleženci sodobnih oboroženih konfliktov. Ta dva primera sta namreč uveljavila večji pomen zasebnih vojaških in varnostnih podjetij, prav tako pa so se v prikrite specialne operacije (angl. »covert actions«) vse dejavneje vključevale tudi obveščevalne službe. Pa vendar o tem ne bomo pisali obsežneje, pač pa se bomo dotaknili še enega pojava, ki je postal v zadnjem času zelo nejasen, to je vloga družboslovnih znanosti v protiuporniških operacijah. Tema je vsekakor postala zanimiva tudi širši javnosti, zlasti po prikazu filma Human Terrain, katerega avtor je raziskovalec mednarodnih odnosov James Der Derian. Ali je torej vključitev znanstvenikov (angl. »embedding«) v neposredno podporo vojaškim operacijam moralno oziroma znanstveno sporna ali je to nekaj novega? Kar zadeva spornost, se nam vsekakor vsiljuje primerjava z bojnim formacijskim novinarstvom (angl. »embedded journalism «), ki pa je vzdignilo precej manj prahu kot uporaba predvsem družboslovne znanosti v neposredne vojaške namene. V kontekstu prikaza razprav Donne Winslow bomo zato predstavili tudi njen prispevek v knjigi Mission Critical: Smaller Democracies'Role in Global Stability Operations z naslovom Anthropology and Cultural Awareness for the Military. V njem avtorica natančno prikaže pomen antropologije in tudi kulturne empatije/ozaveščenosti, ki postaja v sodobnih oboroženih silah vse pomembnejša kategorija.

Brez dvoma so vse protiuporniške operacije usmerjene k človeškemu dejavniku, kajti bistvo teh operacij ni nadzor nad naravnim okoljem, pač pa nad ljudmi. Glavni element operacijskega okvira protiuporništva je zato razumevanje nasprotnikovega človeškega dejavnika. V ta namen je Pentagon angažiral družboslovce, zlasti antropologe, da bi pomagali poveljnikom na terenu pri njihovih stikih z lokalnim prebivalstvom. Antropologija, poznana tudi kot etnologija, se nanaša na znanstveno proučevanje kultur. Izhaja iz razmer, ki zahtevajo praktično upravljanje kulturnih razlik (Pels in Selemink v Winslow, 2010). Danes so predstavniki ameriške vojske najeli antropologe predvsem zato, da jim pomagajo pri njihovem delovanju v Iraku in Afganistanu. Da bi pa razumeli to delovanje, je treba odnos antropologije do varnostnega sektorja predstaviti malce širše. Ta zgodovina je namreč stara že skoraj 200 let, vsaj kar zadeva ZDA. Ameriško ministrstvo za obrambo je namreč že med indijanskimi vojnami 1861-1865 spoznalo pomen kulture kot dejavnika v bojevanju. Kot ugotavlja Hinsley (v Winslow, 2010), je bilo vlaganje v obstoj oziroma analizo sovražnika, proti kateremu so uporabili vso svojo motivacijo, izredno intenzivno. Pa vendar so bili na začetku vojaški častniki bolj ali manj etnografi, zapisovalci njim 
neznanim kultur, zato so že po ameriški državljanski vojni v vojsko novačili prave antropologe. Med prvo svetovno vojno sta pomembna in nadarjena antropologa Richard Burton in Snouk Hurgronje delovala kot vohuna za britansko in nizozemsko vojsko (Pels in Selemink v Winslow, 2010), prav tako pa so bili tudi drugi družboslovci zelo dejavni na eni ali drugi v vojno vpleteni strani. Znani sociolog Emile Durkheim je tako pisal propagandne pamflete za francosko vlado, nemški antropologi pa so merili in slikali ujete nasprotne vojake, da bi ugotovili rasne in nacionalne posebnosti (Price v Winslow, 2010). Tako je že takoj po prvi svetovni vojni Franz Boas, ustanovitelj prvega znanstvenega ameriškega antropološkega oddelka na Columbia University, obsodil takšno zavzetost svojih kolegov in jo označil celo kot prostituiranje znanosti. Zaradi teh stališč so ga izključili iz ameriškega antropološkega združenja. Vendar pa je duh ušel iz steklenice in druga svetovna vojna je bila totalna tudi v smislu uporabe vseh vrst znanstvenih dosežkov. Tako so se dejavno vključili v vojna prizadevanja priznani antropologi Clyde Kluckhohn, Margaret Mead, Ruth Benedict in Gregory Bateson. Sodelovali so pri obveščevalnih analizah, interniranju Američanov japonskega porekla, prav tako so analizirali begunsko problematiko (Gonzales, Gusterson in Prize v Winslow, 2010). Psihologi in antropologi so analizirali tudi učinke zavezniških bombardiranj nasprotnikovih vojaških in civilnih zmogljivosti. Seveda pa zavzetost nemških in japonskih družboslovcev ni bila nič manjša. Nemški so zlasti razvijali t. i. kvaziznanost, ki je podpirala rasno politiko tretjega rajha, japonski pa so podprli svojo državo z informacijami in analizami pri okupaciji Kitajske.

Antropologi pa so imeli pomembno vlogo tudi med hladno vojno. Price (v Winslow, 2010) tako ugotavlja, da so bili v ZDA antropologi na začetku hladne vojne močno nadzorovani, pa ne zaradi simpatiziranja s komunisti oziroma da bi imeli marksistično prepričanje, pač pa zaradi njihove družbene zavzetosti, ki se je nanašala na rasno vprašanje in enakopravnost v ZDA. Seveda so bili mnogi dejavni tudi v obveščevalnih službah. Cia je tako povsem odprto financirala antropološke projekte, na primer Human Relations Area Files. Povezava med družboslovno znanostjo in varnostnim sektorjem je bila praktično vedno prisotna, zlasti pa je postala pomembna, ko so se velike sile vse bolj zapletale v asimetrične spopade in so morale razvijati protiuporniške strategije. Te pa tako rekoč vseskozi slonijo na človeškem obveščevalnem elementu (HUMINT), kajti v protiuporniškem delovanju se ključne informacije vedno dobijo v medčloveški interakciji (Skelton v Winslow, 2010). Zlasti zadnji konflikti so dokazali, da velike sile tudi s svojimi sofisticiranimi obveščevalnimi, sledilnimi, nadzornimi in drugimi zmogljivostmi TECHINT ne morejo prodreti v glave nasprotnikov. Za to vse nujneje potrebujejo razvoj človeških obveščevalnih zmogljivosti. Tako je leta 2005 antropologinja Montgomery McFate (v Winslow, 2010) objavila kontroverzna članka, v katerih zagovarja načela koncepta HTS, kajti po njenem je za zmago v Afganistanu in Iraku enako kot druga sredstva treba razumeti tamkajšnje prebivalstvo in njihovo kulturo. To pomanjkanje kulturne pozornosti pa je po njenem rezultat Powell-Weinbergerjeve doktrine, ki je dajala prednost velikim vojaškim operacijam pred protiuporniškim delovanjem (»counterinsurgency«). Čeprav je ta doktrina doživela neuspeh v mirovnih operacijah na Haitiju, v Somaliji in Bosni ter med drugo zalivsko vojno, pa je šele doktrina, ki jo je razvil general Petraeus (Counterinsurgency Field Manual), povrnila pomen 
razumevanja kulture. Tako se beseda kultura $\mathrm{v}$ tem dokumentu pojavi kar 80-krat. (US Army v Winslow, 2010).

HTS kot način neposrednega vključevanja antropologov, lingvistov in drugih družboslovcev v bojne enote so sicer različna akademska (antropološka) združenja močno kritizirala, po drugi strani pa je vse več zahodnih vojsk, ki si prizadevajo uvesti kulturno ozaveščenost in znanje v vojaški izobraževalni sistem. Tako je celo ameriški predsednik Barack Obama poudaril, da je kulturna ozaveščenost ena od temeljnih prvin oboroženih sil 21. stoletja, ki ne morejo več temeljiti zgolj na tehnološki večvrednosti. Tako bo morala vojska bistveno več vlagati v učenje tujih jezikov, poznavanje tujih kultur in človeško obveščevalno dejavnost. Le tako se bo lahko spoprijela z novimi izzivi in nalogami. Seveda pa bo morala najprej take »kulturne« operacije izvajati sama. Zato se lahko strinjamo z avtorico, da je HTS, kot je bil mišljen za potrebe Iraka in Afganistana, bolj ad hoc poskus, da se pride do družboslovnih znanj po bližnjici. Po njenem mnenju je zato mnogo bolje, da civilni družboslovni strokovnjaki proučujejo vojsko in obveščevalne službe od znotraj, obenem pa vojaško in obveščevalno osebje izobražujejo o njihovi lastni organizacijski kulturi ter o drugih kulturah in družbah. Le tako bo vojska lahko izvajala svoje lastne »kulturne obveščevalne operacije«.

Sklep Znanstveni in strokovni opus Donne Winslow je širok. V prispevku smo obravnavali le nekatere ključne teme z vojaško-varnostnega področja, ki jim je posvečala največ pozornosti, z drugimi, ki so bile zgolj antropološke in etnološke, se nismo ukvarjali (npr. tematika Nove Kaledonije). Proučevanje vojaške kulture je bila verjetno ena njenih temeljnih raziskovalnih ambicij, pri čemer je zaradi odkritih nepravilnosti v kanadski vojski imela za svoje delo tudi veliko snovi. Proučevanje kulture je povezovala s proučevanjem vojske na splošno, od njene strukture do razvoja in delovanja. Vključila se je tudi v moderne razprave o globalizaciji in varnosti, kot antropologinjo pa jo je seveda zanimal projekt Human Terrain System. Analiza del Donne Winslow pokaže, da se je vedno lotevala težkih družbenih tem. Njena dela imajo jasno tezo, ki jo skozi besedilo smiselno in pronicljivo utemeljuje. Ob tem kaže spoštovanje dela kolegov, saj tuje avtorstvo vestno navaja. Moelker (2010) opozori še na eno lastnost njenega dela, in sicer na njeno večkratno preverjanje trditev. Za vsako zapisano trditev naj bi imela kar štiri reference. V digitalnih bazah publikacij najdemo kar nekaj njenih recenzij oziroma kritik, kar kaže na njeno študioznost in spremljanje dela drugih znanstvenikov. Kritike je pogosto objavljala v reviji Pacific Affairs. Tako najdemo kritike knjig z etnografsko tematiko (Winslow, 1991; 1997a), zanimala so jo dogajanja v Somaliji (Winslow 1997b) ter obnova Iraka in Afganistana (Winslow, 2007). Kot udeleženko konferenc in posvetov smo jo (s)poznali tudi avtorji prispevka. Tako se je med drugim udeležila konference ERGOMAS v Portorožu septembra 2002 in svetovnega kongresa sociologije julija 2010 v Göteborgu na Švedskem, kjer smo jo srečali zadnjič. 


\section{Literatura}

1. Belanger, D., 2005. The Canadian Distinctiveness into the XXIst Century - La distinction canadienne au tournant du XXIe siecle. Comment. American Review of Canadian Studies, Autumn 2005.

2. Donna Winslow.com. http://members.chello.nl/d.winslow2, 8. 4. 2013.

3. Journal of Military and Strategic Studies, Winter 2004, Vol. 6, Issue 3 Centre. About the Author: Donna Winslow. http://www.jmss.org/jmss/index.php/jmss/article/view/214/231, 8. 4. 2013.

4. Moelker, R., 2010. In memoriam Donna Winslow. Newsletter, November 2010. ISAResearch Committee 01: Armed Forces \& Conflict Resolution.

5. Pinch, F. A tribute to Dr. Donna Jean Winslow. http://www.resmilitaris.net/ ressources/10139/27/res_militaris-in_memoriam-gayle_janowitz_and_donna_winslow en_pdf, 8. 4. 2013.

6. Soeters, L. J., D. J. Winslow in A. Weibull, 2003. "Military Culture." V Guiseppe Cafforio (ur.), Handbook of the Sociology of the Military. Springer Science and Business Media B.V., str. 237-254.

7. Winslow, D., 1991. Cultural Identity and Ethnicity in the Pacific. Edited by Jocelyn Linnekin and Lin Poyer. Honolulu: University of Hawaii Press. 1990. Book Review. Pacific Affairs, Vol. 64, No. 2 (Summer), str. 285-286.

8. Winslow, D., 1997a. Chroniques Kanak. L'ethnologie en marche. By Alban Bensa. Paris: Ethnies-Documents, Vol. 10, No. 18-19, Automne, 1995. Book Review. Pacific Affairs, Vol. 70, No. 2 (Summer), str. 305-286.

9. Winslow, D., 1997b. Networks of Dissolution: Somalia Undone. Anna Simons. Boulder, CO: Westview Press, 1995. Book Review. Armed Forces \& Society, Vol. 24, Fall.

10. Winslow, D., 1998. Misplaced Loyalties: The Role of Military Culture in the Breakdown of Discipline in Peace Operations. The Canadian Review of Sociology and Anthropology. August 1998, 35, 3, str. 345-367.

11. Winslow, D., 1999. »Rites of Passage and Group Bonding in the Canadian Airborne." Armed Forces and Society. 25(3), str. 429-457.

12. Winslow, D., 2002. The Role of Religion in Conflict and Reconciliation in Bosnia Herzegovina. V J. D. Gort, H. Jansen and H. M. Vroom (eds.), Religion, Conflict and Reconciliation. Multifaith Ideas and Realities. Amsterdam: Rodolpi, str. 340-355.

13. Winslow, D., 2002a. »Women in the Canadian Forces: Between Legal and Social Integration. « Current Sociology, 50 (2). 641-667.

14. Winslow, D., 2002b. Strange Bedfellows: NGOs and the Military in Humanitarian Crises. The International Journal of Peace Studies. Vol. 7, No. 2, Autumn/Winter 2002.

15. Winslow, D., 2003a. The Commission of Inquiry into the deployment of Canadian forces in Somalia: an illustration of the public impact of parliamentary reports on security issues. $V$ Parliamentary oversight of the security sector: Principles, mechanisms and practices. Geneva: DCAF, str. 82-83 (Box No. 33).

16. Winslow, D., 2003b. Leadership Challenges in Peace Operations. Some Observations Concerning the Canadian Experience. V P. Essens, A. Vogelaar, E. Tanercan, D. Winslow (eds.), The Human in Command: Peace Support Operations. Amsterdam: Mets \& Schilt/ Breda: KMA, str. 174-191.

17. Winslow, D., 2003c. The Canadian Military in the Security Environment of the 21st century. V Chad Garfied, Karen L. Gould (ur.), The Canadian Distinctiveness into the XXIst Century - La distinction canadienne au tournant du XXIe siecle. University of Ottawa press.

18. Winslow, D., 2003d. Human Security - 1st draft. Paper presented to CeMiSS Conference »Globalization, Uncertainty, New Conflicts.«Rome. http://members.chello.nl/d.winslow2/ Military/Rome3.doc 
19. Winslow, D., 2004. Misplaced Loyalties: The Role of Military Culture in the Breakdown of Discipline in Two Peace Operations. Journal of Military and Strategic Studies, Winter 2004, Vol. 6, Issue 3.

20. Winslow, D., 2007. Book Review: Fukuyama, F. ed. (2005). Nation-building: Beyond Afghanistan and Iraq. Baltimore, MD: John Hopkins University Press. Armed Forces \& Society, Vol. 33, July, str. 652-655.

21. Winslow, D., 2010. Anthropology and Cultural Awareness for the Military. V Mission Critical: Smaller Democracies'Role in Global Stability Operations, ed. C. Leuprecht, J. Troy, and LCol (ret'd) D. Last. Montreal and Kingston: Queen's Policy Studies Series, McGill-Queen's University Press.

22. Winslow, D. in C. Dandeker, 2000. „On the Need to be Different. Recent Trends in Military Culture."V Douglas Bland (ur.), Backbone of the Army. Non Commissioned Officers of the Future Army. Montreal: McGill Queen's University Press, str. 47-67.

23. Winslow, D. in Moelker, R., 2002. Chechnya, Caught between Globalization from Above and Globalization from Below. VKoimann et al (ur.), Conflict in a Globalising World. Essays in Hounor of Peter Kloos. Van Gorcum, Assen, str. 211-228.

24. Winslow, D., C. Klep, 2004. The Public Inquiry into the Canadian Peace Mission in Somalia. V Hans Born, Haeiner Hänggi (ur), The 'Double Democratic Deficit': Parliamentary Accountability and the Use of Force Under International Auspices. Ashgate.

25. Winslow, D., L. Heinecken in J. L. Soeters, 2003. "Diversity in the Armed Forces. «V G. Cafforio (ur.), Handbook of the Sociology of the Military. Springer Science and Business Media B.V., str. 299-310.

26. Winslow, D.: Gender and Military Sociology. Swedish National Defence College. Dostopno na: http://www.almc.army.mil/ALU_CULTURE/docs/Gender\%20and\%20 Military\%20Sociology.pdf. 